\title{
PENGARUH KEPUASAN DAN DISIPLIN KERJA TERHADAP KINERJA KARYAWAN BANK DI KOTA BATAM
}

\author{
Rizki Novriyanti Zahara', Hajan Hidayat ${ }^{2)}$ \\ 1) Jurusan Manajemen Bisnis, Politeknik Negeri Batam, Batam 29461, email: kikinovriyanti @ gmail.com \\ 2) Jurusan Manajemen Bisnis, Politeknik Negeri Batam, Batam 29461, email: hajan@polibatam.ac.id
}

\begin{abstract}
Abstrak - Penelitian ini bertujuan untuk mengetahui dan menganalisis bagaimana pengaruh kepuasan kerja dan disiplin kerja terhadap kinerja karyawan. Pendekatan metode yang digunakan untuk pengambilan sampel adalah teknik purposive sampling. Responden yang digunakan dalam penelitian ini sebanyak 173 karyawan yang bekerja pada bank BUMN di Batam. Untuk menentukan besarnya pengaruh variabel independen terhadap dependen digunakan analisis regresi berganda dengan bantuan aplikasi SPSS 22.0. Berdasarkan hasil uji t diperoleh nilai $\mathrm{t}$ hitung $3.979>\mathrm{t}$ tabel 1.973 yang berarti $\mathrm{H} 1$ diterima dan nilai $\mathrm{t}$ hitung $4.623>\mathrm{t}$ tabel 1.973 yang berarti H2 diterima. Semakin tinggi kepuasan yang terpenuhi dan semakin tinggi disiplin kerja yang dimiliki karyawan maka semakin tinggi pula kinerja karyawan tersebut. Berdasarkan hasil penelitian yang dilakukan, dapat disimpulkan bahwa ada pengaruh yang signifikan antara variabel kepuasan kerja dan disiplin kerja terhadap kinerja karyawan bank BUMN di Batam.
\end{abstract}

Kata Kunci : Kepuasan Kerja, Disiplin Kerja, Kinerja Karyawan.

\begin{abstract}
This study aims to identify and analyze the influence of job satisfaction and work discipline on employee performance. Approach method used for sampling is purposive sampling technique. Respondents were used in this study were 173 employees working in state-owned banks in Batam. This study uses regression analysis to examine how the influence of these two variables on the performance of employees with SPSS 22.0 application. Results of the $\mathrm{t}$ test obtained by value $\mathrm{t}$ count 3,979>t table 1,973, which means that $\mathrm{H} 1$ is accepted and $\mathrm{t}$ value 4,623>t table 1973, which means $\mathrm{H} 2$ is accepted. The higher the satisfaction is fulfilled and the higher discipline of work that employees have the higher the employee's performance. Based on the results of research conducted, it can be concluded that there is influence between the variables of job satisfaction and work discipline on employee performance state-owned banks in Batam.
\end{abstract}

Keywords: Job satisfaction, Discipline, Employee Performance.

\section{PENDAHULUAN}

\section{Latar Belakang}

Perbankan merupakan lembaga keuangan yang bergerak dibidang jasa yang memberikan pelayanan dan kepercayaan kepada nasabah untuk dapat menyimpan dananya di bank. Bank-bank baru milik swasta membuat persaingan bisnis perbankan semakin ketat sehingga menjadikan bank BUMN selalu berusaha melakukan perbaikan, baik dari segi sumber daya manusia, teknologi, dan pelayanan agar dapat menjadi yang terbaik untuk nasabah.

Keberadaan sumber daya manusia mempunyai peranan penting dalam memberikan pelayanan terbaik kepada nasabah. Manajemen sumber daya manusia berperan untuk mengarahkan dan mengembangkan potensi sumber daya manusia agar menjadi lebih kreatif dan inovatif, karena sumber daya manusia menjadi penggerak utama dari semua kegiatan dan perencanaan yang dilakukan untuk keberlangsungan hidup perusahaan.
Beberapa penelitian mengaitkan kinerja karyawan dengan kepuasan yang dimiliki karyawan. Hasil studi empiris (Khan et al, 2012) yang meneliti tentang pengaruh kepuasan kerja terhadap kinerja karyawan menunjukkan bahwa kepuasan kerja berpengaruh signifikan terhadap kinerja karyawan.

Sedangkan hasil penelitian Balouch (2014) menunjukkan bahwa kepuasan kerja berpengaruh terhadap kinerja, loyalitas karyawan dan perputaran kerja karyawan (turnover). Karyawan yang mempunyai kepuasan terhadap pekerjaannya sudah tentu memiliki loyalitas terhadap perusahaan, ia akan melakukan pekerjaan yang dibebankan kepadanya dengan penuh tanggung jawab.

Sementara itu, penelitian yang dilakukan oleh Mardana (2015) memberikan bukti bahwa disiplin kerja berpengaruh signifikan terhadap kinerja karyawan Bank Riau Kepri Cabang Batam. Hasil penelitian Mardana (2015) didukung oleh penelitian Katiandagho (2014) yang menunjukkan bahwa disiplin kerja memiliki pengaruh positif terhadap kinerja pegawai. Sikap disiplin kerja yang baik ditunjukkan dengan bagaimana karyawan mampu mengikuti aturan - aturan perusahaan, mengerjakan 
tugas tepat waktu dan tidak menghambat bidang pekerjaan yang lain. Dengan adanya kedisiplinan pada karyawan diharapkan mampu menghasilkan kinerja yang optimal.

\section{Rumusan Masalah}

1. Bagaimana pengaruh kepuasan kerja terhadap kinerja karyawan.

2. Bagaimana pengaruh disiplin kerja terhadap kinerja karyawan.

\section{Tujuan Penelitian}

Tujuan dari penelitian ini adalah untuk memberikan bukti empiris bahwa kepuasan kerja memiliki pengaruh terhadap kinerja karyawan dan disiplin kerja memiliki pengaruh terhadap kinerja karyawan yang bekerja di sektor perbankan Kota Batam. Sehingga hasil penelitian ini dapat menjadi sebuah informasi untuk mengetahui faktor yang mempengaruhi kinerja karyawan.

\section{LANDASAN TEORI}

\subsection{Kepuasan Kerja}

Teori Keadilan

Teori ini telah dikembangkan oleh Adam. Teori ini mengemukakan bahwa seseorang akan puas atau tidak puas, tergantung pada ada atau tidak adanya keadilan. Menurut teori ini, komponen utama dalam teori keadilan adalah input, hasil, keadilan dan ketidakadilan. Setiap karyawan akan membandingkan rasio input hasil dirinya dengan hasil input yang dihasilkan orang lain.

Kepuasan kerja merupakan sesuatu yang bersifat individual. Setiap individu memilki tingkat kepuasan yang berbeda sesuai dengan sistem nilai yang berlaku pada dirinya. Menurut Handoko (2001) kepuasan kerja adalah keadaan emosional karyawan yang menyenangkan atau tidak menyenangkan terhadap tugas atau pekerjaan yang telah dibebani. Kepuasan kerja adalah sikap umum terhadap pekerjaan seseorang yang menunjukkan perbedaan antara jumlah penghargaan yang diterima pekerja dan jumlah seharusnya mereka terima (Robbins, 2003).

Berdasarkan pendapat diatas dapat disimpulkan bahwa kepuasan kerja adalah sikap emosional karyawan terhadap pekerjaan dengan membandingkan jumlah hasil yang diterima dan jumlah yang seharusnya diterima.

Faktor-faktor yang mempengaruhi kepuasan kerja berdasarkan Job Descriptive Index (JDI), yaitu :

1. Gaji atau imbalan

2. Promosi

3. Hubungan dengan rekan kerja

4. Hubungan dengan supervisor

5. Pekerjaan itu sendiri

\subsection{Disiplin Kerja}

Teori Pembentukan Perilaku

B.F Skinner mengemukakan pendekatan yang mempengaruhi dan merubah perilaku kerja yaitu teori pembentukan perilaku atau sering disebut behavior modification. Teori ini berasumsi bahwa perilaku individu dapat dibentuk dan diarahkan kearah aktivitas pencapaian tujuan.

Pendekatan ini berdasarkan atas hukum pengaruh (law of effect), dimana perilaku yang diikuti dengan konsekuensi pemuasan cenderung dapat diulang, sedangkan perilaku yang diikuti konsekuensi hukuman cenderung tidak diulang. Dengan demikian perilaku individu di waktu yang akan datang dapat diperkirakan atau dipelajari dari pengalaman masa lalu. Sehingga karyawan berusaha untuk bekerja sama dan meningkatkan kinerjanya bagi perusahaan.

Disiplin kerja adalah alat yang digunakan manajer untuk berkomunikasi dengan karyawan agar bersedia untuk mengubah perilaku serta sebagai upaya untuk meningkatkan kesadaran dan kesediaan karyawan dalam mentaati peraturan perusahaan (Rivai, 2009). Menurut Siagian (2013) disiplin merupakan bentuk pelatihan yang berusaha memperbaiki dan membentuk pengetahuan, sikap dan perilaku karyawan sehingga para karyawan secara sukarela berusaha bekerja secara kooperatif dengan karyawan yang lain serta meningkatkan prestasi kerjanya.

Berdasarkan pendapat di atas, dapat disimpulkan bahwa disiplin kerja merupakan sikap atau bentuk kepatuhan karyawan terhadap peraturan yang berlaku diperusahaan dan kesediaan karyawan akan tugas dan pekerjaan yang dibebankan.

Faktor-faktor penilaian disiplin kerja (Dharmawan, 2011) yaitu :

1. Absensi atau kehadiran

2. Ketaatan pada kewajiban dan peraturan

3. Bekerja sesuai prosedur

\subsection{Kinerja Karyawan}

Kinerja umumnya dikatakan sebagai pengukur seseorang pada hasil pekerjaannya. Informasi tentang kinerja merupakan suatu hal yang digunakan untuk mengevaluasi proses kinerja yang dilakukan perusahaan selama ini telah sejalan dengan tujuan yang diharapkan atau belum. Menurut Hermawati (2012) kinerja merupakan hasil kerja seseorang selama periode tertentu dalam melaksanakan tugas dibandingkan dengan standar hasil kerja, target atau sasaran yang telah ditentukan dan telah disepakati.

Menurut Mangkunegara dalam Apriani (2012) kinerja merupakan hasil kerja secara kualitas dan kuantitas yang dicapai seorang karyawan dalam melaksanakan tugasnya sesuai dengan tanggung jawab yang diberikan kepadanya.

Jadi, kinerja merupakan hasil kerja karyawan yang dapat diamati dan dapat diukur. Ukuran kinerja dapat dilihat dari jumlah dan mutu pekerjaan yang 
telah sesuai dengan standar yang ditetapkan perusahaan.

\subsection{Kajian Literatur}

Penelitian terdahulu yang terkait pengaruh kepuasan dan disiplin kerja terhadap kinerja karyawan. Penelitian Khan (2012), meneliti tentang "Pengaruh Kepuasan Kerja terhadap Kinerja Karyawan Studi Empiris Lembaga Kesehatan Pakistan”. Hasil penelitian menunjukkan bahwa kepuasan kerja dan kinerja karyawan menemukan hubungan yang positif, hubungan antara faktor-faktor kepuasan kerja dan kepuasan kerja lebih signifikan dibandingkan dengan kinerja karyawan.

Penelitian Arifin (2014) meneliti tentang "Pengaruh Kepuasan Kerja dan Disiplin Kerja terhadap Kinerja Karyawan". hasil menunjukkan bahwa kepuasan kerja berpengaruh terhadap kinerja karyawan, disiplin kerja berpengaruh terhadap kinerja karyawan, disiplin kerja lebih dominan memberikan pengaruh terhadap kinerja karyawan.

Kemudian penelitian yang dilakukan oleh Yulianto (2014) meneliti tentang "Pengaruh Motivasi Kerja, Disiplin Kerja dan Kepuasan Kerja terhadap Kinerja Karyawan. Hasil penelitian menunjukkan bahwa motivasi berpengaruh positif dan signifikan terhadap kinerja karyawan, disiplin kerja berpengaruh positif dan signifikan terhadap kinerja karyawan, kepuasan kerja berpengaruh positif dan signifikan terhadap kinerja karyawan.

\subsection{Hipotesis}

\section{a. Pengaruh antara Kepuasan Kerja terhadap Kinerja Karyawan}

Terpenuhinya kebutuhan karyawan maka kepuasan kerja yang dirasakan juga semakin tinggi, hal tersebut akan berdampak terhadap kinerjanya. Penting bagi perusahaan untuk memperhatikan kebutuhan-kebutuhan karyawan seperti memberikan jaminan perlindungan keamanan, memberi penghargaan serta kesempatan kerja untuk mengembangkan potensi dirinya, memberi kesempatan untuk berinteraksi dan mengikutsertakan karyawan untuk mengambil keputusan (Darmawan, 2013).

Hasil penelitian Sajangbati (2013) dan Sahlan (2014) menunjukkan bahwa kepuasan kerja mempengaruhi kinerja karyawan. Maka dapat disimpulkan bahwa kepuasan kerja memiliki pengaruh terhadap kinerja karyawan. Dengan demikian hipotesis yang dirumuskan adalah :

$\mathrm{H}_{1}$ : Kepuasan kerja berpengaruh terhadap kinerja karyawan.

\section{b. Pengaruh antara Disiplin Kerja terhadap Kinerja Karyawan}

Sikap disiplin harus ditanamkan dan dibudayakan oleh setiap karyawan agar dapat mendukung tercapainya tujuan perusahaan. Karyawan yang disiplin akan selalu mentaati peraturan yang ditetapkan. Adanya disiplin yang baik mencerminkan seseorang mempunyai tanggung jawab atas pekerjaannya. Menurut Kaindagho (2014) dan Tindow (2014) disiplin kerja berpengaruh positif terhadap kinerja karyawan.

Karyawan yang disiplin saat pergi kerja, saat kerja dan saat pulang kerja serta mengikuti aturan dalam bekerja, biasanya memiliki kinerja yang baik (Raharjo, 2012). Maka dari itu, dapat dapat disimpulkan bahwa disiplin kerja mempunyai pengaruh terhadap kinerja karyawan. Hipotesis yang dirumuskan adalah :

$\mathrm{H}_{2}$ : Disiplin kerja berpengaruh terhadap kinerja karyawan.

Berdasarkan uraian di atas maka peneliti membuat suatu model penelitian sebagai berikut:

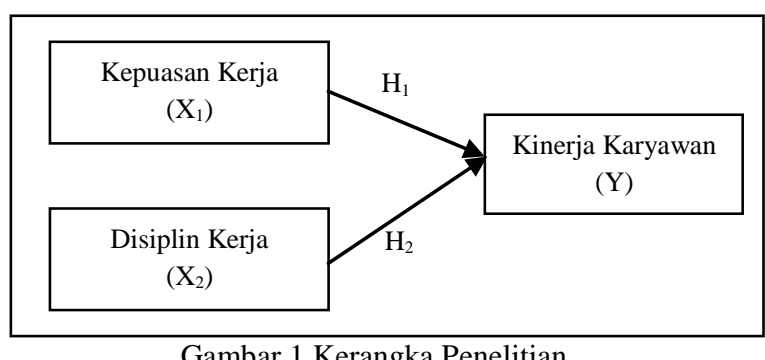

Gambar 1 Kerangka Penelitian

\section{METODE PENELITIAN}

Penelitian ini menggunakan pendekatan kuantitatif. Penelitian ini akan menjelaskan pengaruh antar variabel-variabel yang akan diteliti, yaitu kepuasan kerja dan disiplin kerja terhadap kinerja karyawan.

Kuesioner kepuasan kerja diadopsi dari penelitian yang digunakan Azeem (2010) terdiri dari 16 pertanyaan. Indikator variabel kepuasan kerja yang digunakan meliputi : gaji, promosi, hubungan dengan rekan kerja, hubungan dengan supervisor dan pekerjaan itu sendiri. Kuesioner disiplin kerja diadopsi dari penelitain Dharmawan (2011) terdiri dari 8 pertanyaan. Indikator variabel disiplin kerja meliputi : absensi atau kehadiran, ketaatan pada kewajiban tugas dan peraturan serta bekerja sesuai prosedur. Sedangkan kuesioner kinerja karyawan menggunakan kuesioner dari penelitian Aditya (2010) terdiri dari 6 pertanyaan. Indikator variabel kinerja karyawan meliputi : kualitas, kuantitas, ketepatan waktu, efektifitas, kemandirian, komitmen organisasi. Kuesioner pada penelitian ini menggunakan skala likert 4-poin yang terdiri dari $4=$ sangat setuju, 3= setuju, 2 = tidak setuju, $1=$ sangat tidak setuju.

Obyek penelitian ini adalah seluruh karyawan bank BUMN yang ada di Kota Batam, metode yang digunakan untuk pengambilan sampel dalam penelitian ini menggunakan teknik purposive sampling 
dengan jumlah karyawan yang dapat dijadikan sampel adalah 179 karyawan dan pengolahan data penelitian ini menggunakan program SPSS 22.

Penelitian menggunakan uji validitas dan uji reliabilitas untuk menguji ketepatan data yang digunakan dengan Cronbach Alpha $(\alpha)>0,70$ untuk uji reliabel (Ghozali, 2013). Uji asumsi klasik yang digunakan adalah uji normalitas, uji multikolinearitas dan uji heteroskedastisitas. Pengujian hipotesis menggunakan analisis regresi berganda.

\section{HASIL DAN PEMBAHASAN}

\subsection{Pengujian Instrumen Uji Validitas}

Uji validitas dilakukan untuk mengukur valid tidaknya suatu kuesioner. Kuesioner dikatakan valid jika pertanyaannya mampu untuk mengungkapkan sesuatu yang akan diukur. Semua pernyataan memiliki nilai $r_{\text {hitung }}>r_{\text {tabel }}$ yaitu 0.361 sehingga dapat disimpulkan bahwa semua pernyataan dinyatakan valid.

\section{Uji Reliabilitas}

Pengujian reliabilitas dalam penelitian ini adalah dengan menggunakan alpha Cronbach. Berdasarkan hasil uji reliabilitas semua variabel mempunyai koefisien alpha Cronbach diatas 0,70 sehingga dapat disimpulkan semua variabel dinyatakan reliabel.

\subsection{Uji Asumsi Klasik Uji Normalitas}

Uji statistik yang digunakan untuk menguji asumsi normalitas adalah dengan menggunakan uji normalitas dari Kolmogorov Smirnov. Hasil uji normalitas ditunjukkan sebagai berikut:

\begin{tabular}{|c|c|}
\hline & $\begin{array}{c}\text { Unstandardized } \\
\text { Residual }\end{array}$ \\
\hline Kolmogorov-Smirnov Z & 0.905 \\
\hline Asymp. Sig. (2-tailed) & 0.386 \\
\hline
\end{tabular}

Tabel 1 Hasil Uji Normalitas

Hasil tersebut menunjukkan Kolmogorov smirnov bernilai 0.905 dan nilai signifikansinya 0.386 dimana nilai signifikansi tersebut lebih besar dari 0.05 . Sehingga dapat disimpulkan bahwa data pada penelitian ini terdistribusi normal.

\section{Uji Multikolinearitas}

Uji multikolinieritas bertujuan untuk mengetahui hubungan yang sempurna antar variabel bebas dalam model regresi. Hasil uji multikolinearitas sebagai berikut:

\begin{tabular}{|c|c|c|}
\hline Variabel & Tolerance & VIF \\
\hline Kepuasan Kerja & 0.725 & 1.379 \\
\hline Disiplin Kerja & 0.725 & 1.379 \\
\hline
\end{tabular}

Tabel 2 Hasil Uji Multikolinearitas
Berdasarkan tabel diatas, nilai VIF untuk variabel independen lebih kecil dari 10 dan nilai toleransi lebih besar dari 0,10 . Hal ini membuktikan bahwa tidak terjadi multikolinearitas antar variabel bebas.

\section{Uji Heteroskedastisitas}

Uji heteroskedastisitas bertujuan untuk menguji terjadinya perbedaan varian residual suatu periode pengamatan ke periode pengamatan yang lain. Pengujian heteroskedastisitas dilakukan dengan uji Glejser. Berikut hasil uji heteroskedastisitas :

\begin{tabular}{|c|c|c|}
\hline Variabel & $\mathbf{t}_{\text {hitung }}$ & Sig. \\
\hline Kepuasan Kerja & -0.088 & 0.930 \\
\hline Disiplin Kerja & 0.060 & 0.952 \\
\hline
\end{tabular}

Tabel 3 Hasil Uji Heteroskedastisitas

Hasil menunjukkan nilai $\mathrm{t}_{\text {hitung }}<\mathrm{t}_{\text {tabel }}$ dan nilai signifikansi lebih besar dari 0.05. Sehingga dapat disimpulkan bahwa tidak terjadi heterokedastisitas dalam model regresi.

\subsection{Uji Hipotesis}

\section{Analisis Regresi Berganda}

Analisis regresi digunakan untuk menguji hipotesis tentang pengaruh variabel independen terhadap variabel dependen. Berikut hasil pengujian hipotesis :

\begin{tabular}{|l|c|r|r|c|}
\hline \multirow{2}{*}{ Variabel } & \multicolumn{2}{|c|}{ Koefisien } & \multirow{2}{*}{ Sig. } \\
\cline { 2 - 3 } & B & $\begin{array}{c}\text { Std. } \\
\text { Error }\end{array}$ & & \\
\hline Konstanta & 3.620 & 1.632 & 2.217 & 0.028 \\
\hline Kepuasan Kerja & 0.157 & 0.037 & 4.195 & 0.000 \\
\hline Disiplin Kerja & 0.273 & 0.065 & 4.203 & 0.000 \\
\hline
\end{tabular}

Tabel 4 Analisis Regresi

Berdasarkan hasil analisis di atas dapat dibuat persamaan regresi sebagai berikut:

$$
\mathrm{KK}=3.620+0,157 \mathrm{KK}+0,273 \mathrm{DK}+\mathrm{e}
$$

\section{Uji Signifikansi (Uji Statistik t)}

Uji statistik $\mathrm{t}$ dilakukan untuk mengetahui pengaruh masing-masing variabel independen terhadap variabel dependen secara parsial.

Hasil uji t untuk variabel kepuasan kerja diperoleh nilai $\mathrm{t}$ hitung $=4.195>\mathrm{t}$ tabel $=1.973$ dengan nilai signifikansi sebesar 0.000 ( $\operatorname{sig}<0,05$ ). Sehingga dapat disimpulkan kepuasan kerja berpengaruh signifikan terhadap kinerja karyawan.

Sedangkan hasil uji t untuk variabel disiplin kerja diperoleh $\mathrm{t}$ hitung $=4.203>\mathrm{t}$ tabel $=1.973$ dengan nilai signifikansi sebesar 0.000 ( $\operatorname{sig}<0,05)$. Sehingga dapat disimpulkan bahwa disiplin kerja berpengaruh signifikan terhadap kinerja karyawan. 


\section{Koefisien Determinasi $\left(\mathbf{R}^{2}\right)$}

Koefisien determinasi merupakan untuk mengukur seberapa jauh variabel-variabel independen dalam menerangkan variabel dependen. Nilai koefisien determinasi ditentukan dengan nilai adjusted $R$ square. Nilai adjusted $R$ square dapat dilihat pada tabel berikut :

\begin{tabular}{|c|c|}
\hline Model & Adjusted R Square \\
\hline 1 & 0.322 \\
\hline
\end{tabular}

Berdasarkan tabel di atas, nilai koefisien determinasi sebesar 0,322. Hal ini menunjukkan bahwa variabel kepuasan kerja dan disiplin kerja dapat menjelaskan kinerja karyawan sebesar $32.2 \%$ sedangkan sisanya sebesar $67.8 \%$ dijelaskan oleh variabel lain di luar model.

\section{Pengaruh Kepuasan Kerja Terhadap Kinerja Karyawan}

Hasil pengujian hipotesis $\left(\mathrm{H}_{1}\right)$ diketahui bahwa kepuasan kerja berpengaruh signifikan terhadap kinerja karyawan. Berdasarkan hasil perhitungan maka diperoleh nilai thitung sebesar 4.195 lebih besar dari $\mathrm{t}$ tabel dengan nilai signifikansi hitung sebesar 0,000 lebih kecil dari 0,05 hal ini menunjukkan bahwa hipotesis yang diajukan telah diterima.

Karyawan selalu menginginkan sistem pembayaran dan kebijakan promosi yang adil tidak bermakna ganda dan sesuai dengan harapan mereka. Ketika pembayaran dipandang adil berdasarkan tuntutan pekerjan, level keterampilan individu, dan standar upah yang berlaku, maka kepuasan yang tinggi akan muncul. Karyawan akan mencari kebijakan dan praktik promosi yang adil. Promosi memberikan peluang untuk pertumbuhan pribadi, peningkatan tanggung jawab, dan kenaikan status sosial. Jika seluruh karyawan menganggap keputusan promosi jabatan dalam perusahaan dibuat secara terbuka dan adil, maka akan berpeluang untuk meraih kepuasan dalam pekerjaan mereka. Hal ini mampu memotivasi dan mengarahkan karyawan untuk dapat mengerahkan kinerja terbaiknya.

Hasil penelitian ini didukung penelitian yang dilakukan oleh Wahab (2012) dan Fidella (2014) yang menemukan bahwa kepuasan kerja berpengaruh signifikan terhadap kinerja karyawan.

\section{Pengaruh Disiplin Kerja Terhadap Kinerja Karyawan}

Hasil pengujian hipotesis $\left(\mathrm{H}_{2}\right)$ telah membuktikan terdapat pengaruh yang signifikan antara disiplin kerja terhadap kinerja karyawan. Melalui hasil perhitungan yang telah dilakukan didapat nilai t hitung sebesar 4.203 lebih besar dari $t$ tabel dengan nilai signifikansi hitung sebesar 0,000 lebih kecil dari 0,05 , yang berarti bahwa hipotesis dalam penelitian ini diterima.
Disiplin kerja memiliki peranan tinggi dalam meningkatkan kinerja karyawan. Disiplin kerja yang baik mencerminkan besarnya rasa tanggung jawab seseorang terhadap tugas-tugas yang diberikan kepadanya dengan segala peraturan yang disusun oleh perusahaan. Karyawan yang berperilaku disiplin biasanya akan berhasil dalam pekerjaan karena mereka mampu mengatur apa yang menjadi prioritasnya sehingga kinerjanya juga akan baik (Rivai, 2009).

Hasil penelitian ini didukung oleh hasil penelitian sebelumnya yaitu penelitian Yulianto (2014) dan penelitian Idrus (2015) yang menemukan bahwa disiplin kerja berpengaruh signifikan terhadap kinerja karyawan.

\section{KESIMPULAN DAN SARAN}

\subsection{Kesimpulan}

Berdasarkan hasil penelitian mengenai kepuasan kerja, disiplin kerja dan kinerja karyawan pada karyawan yang bekerja di bank BUMN Kota Batam, dapat ditarik kesimpulan sebagai berikut:

1. $\mathrm{H}_{1}$ diterima, kepuasan kerja berpengaruh signifikan terhadap kinerja karyawan.

2. $\mathrm{H}_{2}$ diterima, disiplin kerja berpengaruh signifikan terhadap kinerja karyawan.

3. Hasil koefisien determinasi diperoleh Adjusted $R$ Square sebesar 0.322 yang menunjukkan bahwa kepuasan kerja dan disiplin kerja memiliki pengaruh $32.2 \%$ terhadap kinerja karyawan bank BUMN di Kota Batam. Sekitar $67.8 \%$ variabel kinerja karyawan dipengaruhi oleh variabel lain.

\subsection{Saran}

Memperhatikan adanya beberapa keterbatasan seperti yang telah disampaikan maka bagi penelitian selanjutnya perlu memperhatikan beberapa saran berikut ini:

1. Dari hasil penelitian yang dilakukan, penting bagi atasan untuk selalu memberdayakan karyawannya ataupun memenuhi kebutuhan karyawan dan mengawasi karyawan untuk bersikap disiplin agar mereka mampu melakukan pekerjaan sesuai aturan yang ada. Sehingga nantinya dapat mempengaruhi hasil kerja karyawan itu sendiri.

2. Penelitian selanjutnya disarankan untuk menggunakan sampel dari perusahaan lain untuk mengetahui bagaimana teori kepuasan kerja dan disiplin kerja di implikasikan, dan dapat pula menambah variabel lain yang berpengaruh terhadap kinerja karyawan. 


\section{DAFTAR REFERENSI}

[1] Aditya, R. R. (2010). Pengaruh Gaya Kepemimpinan, Motivasi dan Disiplin Kerja terhadap Kinerja Karyawan PT Sinar Sentosa Perkasa Banjarnegara.

[2] Apriani, D., \& Eko, H. W. (2012). Pengaruh Motivasi Kepuasan Kerja dan Disiplin Kerja terhadap Kinerja Karyawan pada PT. Sandang Asia Maju Abadi Semarang. Jurnal Mahasiswa Q-MAN Volume I, No. 4 , 76-86.

[3] Arifin, M. R. (2014). Pengaruh Kepuasan Kerja dan Disiplin Kerja terhadap Kinerja Karyawan PT Tri Keeson Utama Garut. Jurnal Unikom.

[4] Arsyenda, Y. (2013). Pengaruh Motivasi Kerja dan Disiplin Kerja terhadap Kinerja PNS (Studi Kasus : BAPPEDA Kota Malang).

[5] As'ad, M. (2000). Psikologi Industri. Yogyakarta: Liberty.

[6] Ayun. (2011). Pengaruh Motivasi, Disiplin dan Kepuasan Kerja terhadap Kineja Karyawan Bagian Produksi CV Cahaya Mandiri. Universitas Negeri Semarang.

[7] Azeem, S. M. (2010). Job Satisfaction and Organizational Commitment among Employee in the Sultanate of Oman. Scientific Research, 295-299.

[8] Balouch, R., Javed, M., \& Hassan, F. (2014). Determinants of Job Satisfaction and its Impact on Employee Performance and Turnover Intentions. International Journal of Learning \& Development Vol. 4, No. 2.

[9] Darmawan, D. (2013). Prinsip - Prinsip Perilaku Organisasi . Surabaya: Pena Semesta.

[10] Dharmawan, I. M. (2011). Pengaruh Kompensaasi, Lingkungan Kerja non Fisik Terhadap Disiplin Kerja dan Kinerja Karyawan. Tesis Pascasarjana Universitas Udayana Denpasar.

[11] Fidella. (2014). Pengaruh Kepuasan dan Motivasi Kerja terhadap Kinerja Karyawan Bank Central Asia Pekanbaru. Jom Fekon Vol 1 No.2 .

[12] Ghozali, I. (2012). Aplikasi Analisis Multivariate dengan Program SPSS. Semarang: BP Univeristas Diponegoro.

[13] Handoko, H. (2001). Manajemen Personalia dan Sumberdaya. Edisi II, Cetakan Keempat Belas Yogyakarta: BPFE.

[14] Hermawati, A. (2012). Pengaruh Motivasi dan Kemampuan terhadap Prestasi Kerja Pegawai Dinas Pendidikan Pemerintah Kota Batu. Jurnal Dinamika Dotcom Vol. 3(2), 107-120

[15] Hestisani, H., Bagia.I.W., \& Suwendra, I. (2014). Pengaruh Motivasi Berprestasi dan Disiplin Kerja terhadap Kinerja Pegawai BKD Kab. Buleleng. e-Journal Bisma Universitas Pendidikan Ganesha Vol. 2.

[16] Idrus, M. S., \& Suci, R. P. (2015). The Influence of Employee Training and Discipline Work against
Employee Performance PT. Merpati Nusantara Airlines (Persero). Review of European Studies Vol. 7, No. 11

[17] Kasmir. (2008). Bank dan Lembaga Keuangan Lainnya. Jakarta: PT Raja Grafindo Persada.

[18] Katiandagho, C., L. Mandey, S., Mananeke, \& Lisbeth (2014). Pengaruh Disiplin Kerja, Kepemimpinan dan Motivasi terhadap Kinerja Pegawai pada PT PLN (Persero) Wilayah Suluttenggo Area Manado. Jurnal EMBA Vol.2 No.3, 1592-1602.

[19] Khan, A. H., \& Muhammad Musarrat Nawaz, M. A. (2012). Impact of job satisfaction on employee performance:An empirical study of autonomous Medical Institutions of Pakistan. African Journal of Business Management Vol. 6 (7), 2697-2705

[20] Mahardikawanto. (2013). Pengaruh Disiplin Kerja Lingkungan Kerja dan Kualitas Kehidupan Kerja terhadap Kinerja Karyawan RSUD Dr. M. Ashari Pemalang. Jurnal Universitas Negeri Semarang.

[21] Mangkunegara, A. P. (2011). Manajemen Sumber Daya Manusia Perusahaan. Bandung: Rosdakarya.

[22] Mardana, Y. F., Harlen, \& Isyandi. (2015 ). Analisis Pengaruh Motivasi, Kemampuan dan Disiplin Kerja terhadap Kinerja Karyawan pada Bank Riau Kepri Cabang Batam. Jurnal Tepak Manajemen Bisnis Vol VII No 1 .

[23] Nugroho, C. A. (2015). Pengaruh Gaya Kepemimpinan dan Disiplin Kerja terhadap Kinerja Pegawai Dinas Pariwisata DIY. Fakultas Ekonomi Universitas Negeri Yogyakarta.

[24] Raharjo, S. T., \& Prawatya, D. A. (2012). Pengaruh Disiplin Kerja dan Budaya Organisasi terhadap Kinerja Karyawan Pabrik Minyak Kayu Putih (PMKP) di Krai Purwodadi. Diponegoro Journal of Management Vol 1 No. 1, 323-331.

[25] Rivai, V. (2009). Manajemen Sumber Daya Manusia untuk Perusahaan dari Teori ke Praktek. Jakarta: PT Raja Grafindo Persada.

[26] Robbins, S. P. (2003). Perilaku Organisasi, Jilid 2. Jakarta: PT. Indeks Kelompok Gramedia.

[27] Sahlan, N. I., Mekel, P., \& Trang, I. (2015). Pengaruh Lingkungan Kerja, Kepuasan Kerja dan Kompensasi terhadap Kinerja Karyawan pada PT. Bank Sulut Cabang Airmadidi. Jurnal EMBA Vol.3 No.1, 52-62.

[28] Sajangbati, I. A. (2013). Pengaruh Motivasi, Disiplin, dan Kepuasan terhadap Kinerja Pegawai PT. Pos Indonesia (Persero) Cabang Bitung. Jurnal EMBA Vol.1 No.4, $667-$ 678.

[29] Siagian, S. (2013). Manajemen Sumber daya Manusia. Bumi Aksara: Jakarta.

[30] Smith, P., Kendalt, L., \& Hullin, C. (1969). The Measurement of Satisfaction in Work and Retirement. 
[31] Wahab, R. (2012). Pengaruh Kepuasan Kerja dan Motivasi Kerja terhadap Kinerja Karyawan PT Bank Mandiri (Persero) Makassar. Skripsi Unhas.
[32] Yulianto, E. A. (2014). Pengaruh Motivasi Kerja, Disiplin Kerja, dan Kepuasan Kerja terhadap Kinerja Karyawan RS. Asy-Syifa' Sambi. Jurnal Universitas Muhammadiyah Surakarta. 